\title{
La Constitución de la Ciudad Autónoma de Buenos Aires. Su análisis a 25 años de la re- forma constitucional argentina de $1994^{*}$ The Constitution of the Autonomous City of Buenos Aires. His 25-Year Analysis of Argentina's 1994 Constitutional Reform
}

Marcelo Alberto López Alfonsín** https://orcid.org/0000-0002-2110-3354

http://dx.doi.org/10.21503/lex.v18i25.2110

\footnotetext{
* El presente artículo tiene su fuente en la conferencia de cierre que el autor pronunciara en el marco del Programa de Actualización en Derecho de la Ciudad Autónoma de Buenos Aires del Departamento de Posgrado de la Facultad de Derecho de la Universidad de Buenos Aires el 27 de Noviembre de 2019. Es un Especial para la revista Lex.

** Juez de la Ciudad Autónoma de Buenos Aires (Argentina). Doctor en Derecho, Área Derecho Constitucional, (Universidad de Buenos Aires). Magíster en Derecho Ambiental (Universidad de Lomas de Zamora). Argentina.

Correo electrónico: mlalfonsin@jusbaires.gov.ar
}

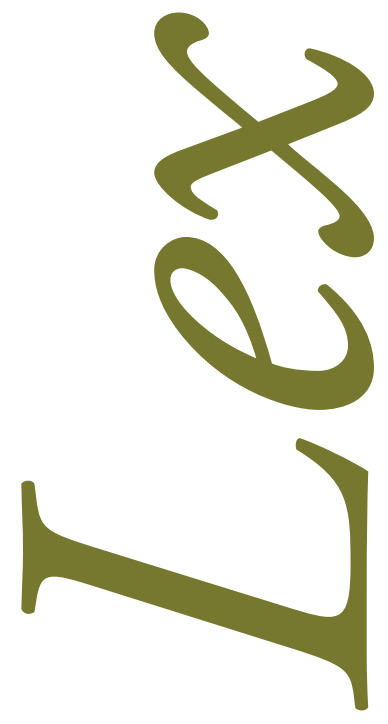




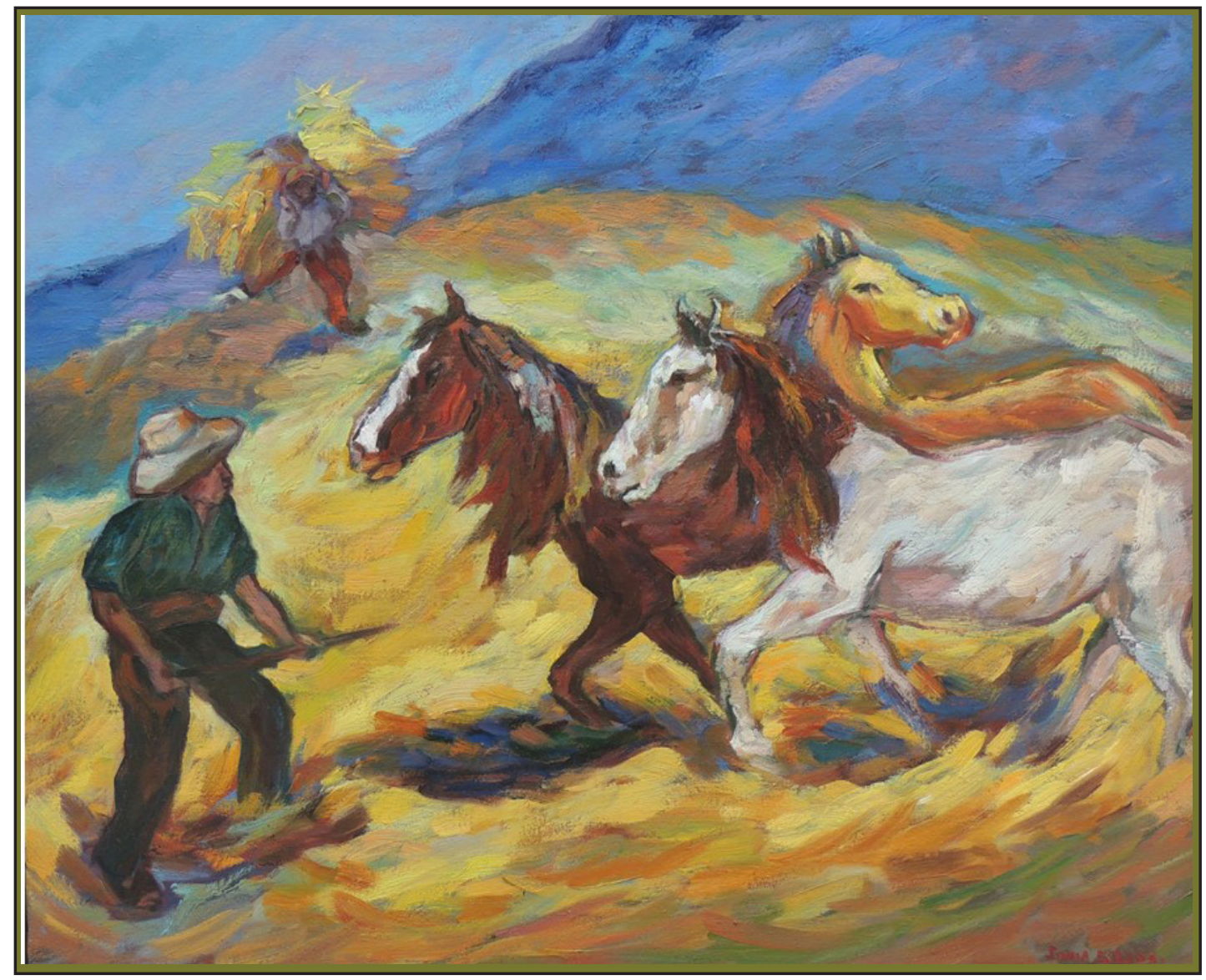

Trilla. Óleo sobre lienzo $65 \times 81 \mathrm{~cm}$. Sonia Estrada Melgarejo (pintora peruana, Ancash) 


\section{RESUMEN}

El trabajo analiza los distintos institutos que forman parte de la Constitución de la Ciudad Autónoma de Buenos Aires de 1996. Ésta fue sancionada en ejercicio del poder constituyente originario por una Convención ad hoc que deliberó como consecuencia del nuevo estatus jurídico-político de la Ciudad otorgado por la reforma constitucional nacional argentina de 1994, con la particularidad que su autonomía debe convivir con la condición de Buenos Aires como capital de la República. Se analizan los derechos fundamentales reconocidos y las políticas especiales que en la materia debe seguir el Estado porteńo. También el juego institucional entre los distintos poderes ejecutivo, legislativo y judicial- y los órganos de control, en el marco de un Estado Constitucional de Derecho. Por último, se realiza un balance de la autonomía porteńa, que en opinión del autor es una asignatura pendiente a más de 25 años de la reforma constitucional argentina de 1994.

Palabras claves: constitución, reforma, democracia, autonomía, balance.

\section{ABSTRACT}

This article analyzes the different institutes that are part of the City of Buenos Aires Constitution since 1996. This was sanctioned in the exercise of the original constitutional power by an ad hoc Convention that deliberated as a result of the new legal-political status of the City granted by the Argentine national constitutional reform of 1994, with the particularity that this autonomy must coexist with the condition of Buenos Aires being also the capital of the Republic. Are analyzed the fundamental rights recognized and the special policies that the Buenos Aires State must follow in this regard. Also the institutional game between the different powers - executive, legislative and judicial - and the control agencies and institutions, within the framework of constitutional rule of law. At last, is carried out a balance of the city of Buenos Aires autonomy, in wich the author's opinion is that is still a pending subject even 25 years after the Argentine constitutional reform of 1994.

Key word: constitution, reform, democracy, autonomy, balance. 


\section{EL ANÁLISIS DEL TEXTO CONSTITUCIONAL PORTEÑO DE 1996 - TÍTULO PRELIMINAR \\ CAPÍTULO PRIMERO - PRINCIPIOS}

Los primeros artículos que integran el Título Preliminar de la Constitución porteña pretenden construir las bases hermenéuticas desde donde comprender la labor legislativa de la Convención Constituyente. Así, el artículo $1^{\circ}$ reafirma la profesión de fe en el federalismo argentino, a la vez que asienta las instituciones autónomas en la forma de gobierno de la democracia participativa. El antecedente de una norma similar introducida en la Constitución del Reino de Espańa en 1978 fue tenido especialmente en cuenta en los debates, si bien allí se define al Estado español como "social y democrático de derecho", definición que ha servido de fuente a una importantísima doctrina y jurisprudencia constitucional. La forma representativa y republicana complementa esta definición ideológica, que marca los senderos por donde transcurrirá el conjunto del plexo normativo. La delimitación competencial que surge del segundo párrafo de este artículo $1^{\circ}$, coloca al "status jurídico" de la Ciudad Autónoma de Buenos Aires a la par de una autonomía provincial.

La condicionalidad expresada en el artículo $3^{\circ}$ _"Mientras la Ciudad de Buenos Aires sea Capital de la República..." - está en perfecta sintonía con similar norma de la Constitución Nacional y con la cláusula de la autonomía del artículo 129 de la Ley Fundamental, en particular su segundo párrafo. Coincidimos con la postura que subraya esta condición como una correcta interpretación de la cláusula transitoria séptima introducida en la reforma de 1994 y sus normas relacionadas (v. gr.: cláusula transitoria tercera de la Constitución de la Ciudad de Buenos Aires), por cuanto el constituyente federal previó expresamente una figura abierta a futuro al resolver la conflictiva "cuestión Capital". Máxime cuando a la fecha aún sigue en vigencia la Ley No 23.512 que establece el traslado de la Capital Federal a los éjidos de las ciudades de Viedma, Carmen de Patagones y Guardia Mitre, más allá de su virtual desuetudo por la retrocesión de las provincias de Río Negro y Buenos Aires de dichos territorios. Un soplo de aire fresco y renovado viene desde dos normas que aplaudimos: la que establece el carácter público de todos los actos de gobierno junto a la supresión de los títulos honoríficos de los funcionarios y cuerpos colegiados - de inspiración morenista-, y la constitucionalización del derecho 
de resistencia, ya incluido en el artículo 36 de la Constitución Nacional. Estas cláusulas democráticas y progresistas se insertan coherentemente con las coordenadas de defensa del Estado de Derecho, cuyo espíritu respira la totalidad de este capítulo introductorio.

Un párrafo aparte merece el mandato contenido en el artículo $6^{\circ}$, por el cual en forma "expresa, permanente e irrenunciable" se impone a las autoridades constituidas la obligación de preservar la autonomía y cuestionar cualquier norma limitatoria de la misma en todas las instancias políticas y judiciales. Si una constitución implica un programa de gobierno para los tiempos y, en alguna medida, un proyecto de vida en común, los constituyentes han recogido esta buena doctrina de la mejor forma.

\section{CAPÍTULO SEGUNDO - LÍMITES Y RECURSOS}

El presente capítulo tiene un vicio de técnica legislativa previa a cualquier consideración, al agrupar en forma conjunta en este Título Preliminar dos cuestiones de naturaleza absolutamente distinta, sin nada en común, cuales son los límites y los recursos de la Ciudad Autónoma de Buenos Aires. Hecha esta salvedad, cabe destacar una vez más el hecho de estar presentes en sus discusiones algunas referencias a la coyuntura política que inevitablemente se vieron reflejadas en el producto final de la labor constituyente al momento del ejercicio del poder constituyente originario porteńo.

Muchas de las contradicciones a las que llevó el tira y afloje con el gobierno nacional por parte de un órgano como la Convención, con amplia mayoría opositora en su conformación, se encuentran resumidas en el artículo $8^{\circ}$. Así, mientras al fijar los límites territoriales se señala que son "los que históricamente y por derecho le corresponden conforme a las leyes y decretos nacionales vigentes a la fecha” - lo cual implica una natural subordinación al derecho federal que podría modificarlos con posterioridad a la entrada en vigencia de la Constitución-, a renglón seguido se la declara "corribereña" del Río de la Plata y del Riachuelo, con la salvedad de que se lo hace "sin perjuicio de las normas de derecho internacional aplicables" y "con los alcances del artículo 129 de la Constitución Nacional”. Es decir, luego de una asumida "capitis diminutio" frente al Estado federal y al conjunto de las provincias argentinas, viene una temeraria declaración de autonomía, subrayada también por la afirmación del "dominio inalienable e imprescriptible de sus recursos naturales", a la manera de la cláusula que introdujo la reforma de 1994 para las provincias con respecto al "dominio originario de los recursos naturales existentes en su territorio" (artículo 124).

Esta verdadera esquizofrenia jurídica -de difícil dilucidación aún para el experto en derecho administrativo- solamente puede ser entendida en el marco de los faraónicos proyectos inmobiliarios del gobierno nacional -léase aeroisla, ciudad judicial, etc.- que aportan poco a la hora de evaluar con sensatez y profundidad el particular "status dominial" de la Ciudad, máxime en virtud de ser Capital Federal y existir establecimientos de utilidad nacional sometidos a la facultad del Congreso de la Nación (artículo 75, inciso 30). Se agrega a esto la situación del puerto porteño, en donde se incurre en donde se incurre en una clara confusión entre dominio y jurisdicción que será fuente de enfren- 
tamiento ineludible, tal como ya se vio reflejado en el proyecto de ley aprobado por el Honorable Senado de la Nación el 18 de Diciembre de 1996 al que aludimos anteriormente.

Esta conflictiva situación se repite en el artículo $9^{\circ}$-en concordancia con el artículo $50^{\circ}$, al establecer que son recursos de la Ciudad Autónoma de Buenos Aires "los ingresos por la explotación de juegos de azar, de apuestas mutuas y de destreza" (inciso 10), hoy en día bajo la órbita de la Lotería Nacional Sociedad del Estado. Los restantes 11 incisos y la cláusula transitoria tercera legitiman a las autoridades locales en el debate sobre el nuevo régimen de coparticipación impositiva instituido por el artículo 75, inciso 2 de la Ley Fundamental, el cual se encuentra en mora con respecto al plazo fijado por la cláusula transitoria sexta de la reforma de 1994 (31 de Diciembre de 1996).

\section{LIBRO PRIMERO. DERECHOS, GARANTÍAS Y POLÍTICAS ESPECIALES}

\section{- TÍTULO PRIMERO. DERECHOS Y GARANTÍAS}

La parte dogmática de la Constitución de la Ciudad de Buenos Aires se inserta dentro de las tendencias más modernas del constitucionalismo comparado, y trae varias novedades que la ponen a la cabeza en la afirmación de los derechos individuales y colectivos. Se tuvieron muy en cuenta en su elaboración las experiencias recientes del derecho público provincial - en especial las 16 reformas introducidas a partir del restablecimiento democrático de 1983 -, y la profundización del garantismo constitucional ya insinuada con la reforma de 1994 a nivel federal. Su ubicación previa a la parte orgánica sigue el modelo nacional, aunque introduce la particularidad de un título referente a Políticas especiales que analizaremos por separado.

El principio general está contenido en el artículo $10^{\circ}$, el cual confirma la línea interpretativa de Germán J. Bidart Campos -que compartimos plenamente- por la cual el garantismo de la Constitución Nacional actúa como "piso", reservando a la parte dogmática local un suplemento que lo enriquezca o mejore, pero sin posibilidad de restringirlo en un ápice. Algunos autores critican la tendencia del constitucionalismo provincial de incluir un capítulo con esta temática -Néstor Sagües suele hablar de "inflación constitucional"- pero este es un hecho tan frecuente que parece haberse convertido ya en regla. Dos novedades deben ser muy bien recibidas: la clave hermenéutica a favor de la buena fe, con fuente en el derecho privado, y la presunción de operatividad contenida en la última parte de esta norma.

Después de introducir el "derecho a la identidad" -reafirmado por la cláusula transitoria vigésima en lo que hace a la búsqueda de información sobre personas que se presumieren nacidas durante el cautiverio antes del 10 de Diciembre de 1983 -, el artículo llo avanza en una dirección de definidos perfiles progresistas: el "derecho a ser diferente" va en camino a convertirse en un nuevo paradigma 
referencial del ideario antidiscriminatorio. Las acciones positivas a favor de la igualdad real de oportunidades recoge una vertiente teórica introducida en la reforma de 1994, ampliada desde la participación democrática hasta la promoción de políticas públicas que tengan por objeto "la remoción de los obstáculos de cualquier orden que impidan el pleno desarrollo de la persona y la efectiva participación en la vida política, económica o social de la comunidad".

En sintonía, las directrices de los artículos $12^{\circ}$ y $13^{\circ}$ abren el juego a las más favorables teorías modernas de las garantías constitucionales del derecho penal, inclusive erradicando los aberrantes edictos policiales, repudiados por la ciudadanía porteña sin distinción.

Donde se observan claramente mejores resultados en materia de técnica legislativa y se aprovecha al máximo la experiencia reformista de 1994 es en la redacción de los artículos $14^{\circ}$ a $16^{\circ}$, que consagran la acción de amparo, el habeas corpus y el habeas data. En efecto, la consagración expresa de estas garantías constitucionales fueron objeto de un largo y conflictivo debate, tanto en la instancia de la Convención Nacional que introdujo el artículo 43 en el capítulo de "Nuevos derechos y garantías" de la Ley Fundamental, como en ocasión de su reglamentación posterior por parte del Congreso de la Nación. Basta como ejemplo de lo dicho el veto del Poder Ejecutivo Nacional al proyecto de ley de habeas data, y la aún incompleta sanción del proyecto de ley de amparo, dos de las "asignaturas pendientes" de desarrollo constitucional.

En materia de amparo, se ha incorporado la gratuidad de la acción, en concordancia con la exención de costas del accionante salvo temeridad o malicia. Asimismo, se ha incluido expresamente la facultad judicial de declaración de inconstitucionalidad de oficio de la norma en que se funda el acto u omisión lesiva, sepultando interpretaciones restrictivas en sentido contrario. Pero la novedad más trascendente es la no obligatoriedad del agotamiento de la vía administrativa para la procedencia de la acción, recogiendo así la mejor tradición doctrinaria a favor de la amplitud garantista, entre cuyos autores se destacan Humberto Quiroga Lavié y Augusto Mario Morello.

Amén de la salvedad de evitar formalidades procesales que afecten la operatividad del amparo, es fundamental la precisión formulada en materia de derechos colectivos, al extender la legitimación a las "personas jurídicas" defensoras de estos intereses, evitando conflictos que menoscaben la participación de las organizaciones ciudadanas. Hacemos votos para que la Ciudad de Buenos Aires se convierta, en este sentido, en un adalid en la promoción de organizaciones no gubernamentales que propendan a esos fines, ensanchando las bases democráticas de la sociedad porteña.

Con referencia al habeas corpus, es muy plausible la precisión en el plazo en el que el juez actuante debe resolver la petición (24 horas), aún durante la vigencia del estado de sitio. En el habeas data, se ha logrado imponer la postura más amplia en el contenido de esta acción, al seńalar como prioritario el "libre acceso" a todo registro, archivo o banco de datos donde se encuentre la información, sean indistintamente organismos públicos o privados destinados a proveer informes, efectivizando de esta 
manera los mecanismos de resguardo de derechos fundamentales, como es el de la intimidad de las personas.

\section{- $\quad$ TÍTULO SEGUNDO. POLÍTICAS ESPECIALES}

La totalidad de este título ha sido objeto de numerosas críticas por parte de la doctrina constitucional, señalando en general un exceso reglamentarista y una voluntad legislativa que confunde la labor constituyente con las facultades parlamentarias propiamente dichas. Esta observación es válida en gran parte de los 42 artículos que, en 20 capítulos, integran este título, pero debe ser vista dentro de una cada vez más común tendencia a apartarse de la parquedad en el lenguaje constitucional y a avanzar en la definición de los trazos gruesos de la política institucional en cada área. Compartimos el criterio que recomienda prudencia y moderación en la redacción de las cláusulas, a fin de que su eventual falta de vigencia efectiva no reste validez al principio de supremacía constitucional y su consiguiente respeto ciudadano, pero no creemos que corresponda exigir un ascetismo que no se compadece con la idiosincrasia de las tareas que desarrollan quienes encaran el rol constituyente.

El análisis de las disposiciones comunes contenidas en los artículos $17^{\circ}$ y $18^{\circ}$ marca el perfil de las políticas públicas a desarrollar por las autoridades de la Ciudad de Buenos Aires, cualquiera fuere el signo partidario que representen: la superación de la pobreza y la exclusión social, y la promoción del desarrollo humano son sus coordenadas. En esa dirección, la asistencia a las personas con necesidades básicas insatisfechas y el acceso a los servicios públicos de quienes tienen menores posibilidades económicas son dos objetivos prioritarios, procurando para ello compensar las desigualdades zonales dentro del territorio urbano. Para ello, se crea un Consejo de Planeamiento Estratégico (artículo 19º) con una integración marcadamente pluralista, a fin de articular su interacción con la sociedad civil. Este organismo resultará, a la postre, un valioso instrumento en la formulación de estas políticas sectoriales, manteniendo una unidad de criterio basada en el consenso y la participación ciudadana. Analizaremos a continuación muy sucintamente algunos aspectos de cada temática, independientemente de su comentario particular en el articulado.

En materia de salud, la Ciudad ejerce su función indelegable de autoridad sanitaria (artículo $22^{\circ}$ ). La Legislatura sancionará una Ley Básica conforme a los lineamientos establecidos en el artículo $21^{\circ}$ -el plazo para dicha sanción no podrá superar el año desde la instalación del órgano legislativo, según prescribe la cláusula transitoria octava -; asimismo, se crea el Consejo General de Salud, de carácter consultivo, no vinculante y honorario, con representación estatal y de la comunidad. En el área de la educación, la mayor polémica se desató oportunamente en ocasión de la definición del constituyente a favor del carácter público, estatal, laico y gratuito de la misma. Algunos sectores vieron en esto una restricción en cuanto al derecho los padres a decidir la educación familiar, opinión que no compartimos: la responsabilidad indelegable que asume la Ciudad en el artículo $24^{\circ}$ es una razonable toma de posición que en nada contradice el espíritu de la Constitución Nacional ni los tratados internacionales de derechos humanos incorporados por el artículo 75, inciso 22 de la Ley Fundamental. Las facul- 
tades de acreditación, evaluación, regulación y control de la gestión educativa -sean estos servicios prestados por personas privadas o públicas no estatales-, están garantizando de forma indelegable un papel protagónico de la Ciudad en la calidad educativa de sus habitantes (artículo 25\%), siguiendo los lineamientos que prudentemente fije la Ley General (para cuya sanción la Legislatura no tiene un plazo perentorio como el señalado en materia de salud).

El capítulo ambiental (artículos $20^{\circ}$ a $30^{\circ}$ ) trae, también, algunas novedades de importancia. En primer término, la definición del ambiente como "patrimonio común" (artículo 26º en una conquista largamente defendida por el movimiento ecologista desde la Declaración de Estocolmo de 1972 -el primer documento internacional de envergadura convenido en la Conferencia de las Naciones Unidas sobre Ambiente Humano- que sitúa indubitablemente la naturaleza jurídica de este derecho entre los llamados "de incidencia colectiva". La misma normativa sigue los lineamientos del artículo 41 de la Constitución Nacional, pero agrega la polémica declaración de la Ciudad como "territorio no nuclear", arriesgando una definición de imprevisibles consecuencias en la instancia de elaboración de una política ambiental responsable. Las variables del proceso de ordenamiento territorial que deben ser instrumentadas a tenor del artículo $27^{\circ}$ amplía favorablemente el marco favorable a un desarrollo sustentable. Cabe destacar la amplia participación de las organizaciones no gubernamentales en la discusión de las mismas, al igual que en la inclusión con carácter obligatorio de la elaboración de un Plan Urbano Y Ambiental (artículo 29\%). Las limitaciones impuestas en cuanto a la prohibición de ingreso a la Ciudad de residuos peligrosos -en sintonía con la Ley No 24.051, de aplicación en el ámbito federal- de la utilización de métodos, productos, servicios o tecnologías no autorizadas o prohibidas en su país de producción, de patentamiento o de desarrollo original -según la legislación derivada que fije los plazos de reconversión de los que estén actualmente autorizados- son saludables signos de autonomía, al igual que la obligatoriedad de la evaluación previa del impacto ambiental de todo emprendimiento público o privado susceptible de "relevante efecto" (artículo 30). Es indudable que en la labor constituyente local se pudo avanzar en la introducción de estas modernas figuras, a diferencia de la Convención de Santa Fe, cuya labor se vio restringida en esta temática por la propia Ley No 24.309 que declaró la necesidad de la reforma, la cual al habilitar el punto a debatir lo hizo para ser introducido en una sola norma -el contenido del derecho/ deber del articulo 41-, más allá de la decisión de elaborar también su consecuente garantía -el amparo colectivo del segundo párrafo del artículo 43 -.

El capítulo quinto incurre en un exceso reglamentarista muy criticable, pues era suficiente con el reconocimiento del derecho a una vivienda digna y a un hábitat adecuado. El capítulo cultural, por su parte, utiliza un lenguaje técnico algo farragoso para el no iniciado en la temática, aún cuando incorpora la garantía de preservación, recuperación y difusión del patrimonio cultural, cualquiera sea su régimen jurídico y titularidad, afianzando así su condición de "interés difuso o colectivo". La inclusión de dos capítulos referidos al deporte -séptimo-y al turismo -vigésimo- subrayan el perfil del constitucionalismo social. 
En materia de seguridad, los artículos $34^{\circ}$ y $35^{\circ}$ avanzan con respecto a las limitaciones impuestas por la Ley No 24.588 con un tono marcadamente desafiante, que deberá ser inevitablemente moderado al momento de entablar negociaciones con el gobierno nacional. La creación del Consejo de Seguridad y Prevención del Delito, en el ámbito del Poder Ejecutivo, no aporte claridad por la indefinición de su figura institucional, si bien su carácter es puramente consultivo. Estimamos que la cláusula transitoria segunda de la Constitución adquiere aquí una virtualidad jurídica indudable, al dejar en suspenso la vigencia de esta normativa hasta una eventual reforma legislativa a nivel nacional.

Sin lugar a dudas, el capítulo noveno abre el camino para más de una polémica. Su articulado comienza con una reafirmación de lo ya esbozado a nivel nacional con la reforma de 1994, en el sentido de reformular el principio de igualdad ante la ley (artículo 15 de la Ley Fundamental) por el de "igualdad real de oportunidades de trato", referido al acceso y goce de todos los derechos civiles, políticos, económicos, sociales y culturales, permitiendo su ejercicio efectivo en todos los ámbitos, organismos y niveles, con el "piso" de los parámetros vigentes al tiempo de la sanción de la Constitución. Dicho mandato se amplía en el caso de los partidos políticos hasta los cargos de conducción y al propio manejo financiero, ratificando el artículo $36^{\circ}$ el controvertido "cupo femenino", pero con mayores precisiones en su alcance.

Algunos autores -Sagües, entre ellos — ven en el primer párrafo del artículo $37^{\circ}$ una ventana por la cual se podría justificar la introducción del aborto, especialmente al darle jerarquía constitucional a los denominados "derechos reproductivos" y a la planificación familiar, y alertan sobre la contradicción que ello acarrearía con el objetivo planteado en el segundo párrafo de la misma norma, al promover el constituyente local la protección integral de la familia.

Más allá de una interpretación de buena fe (que no es el caso de Rodolfo Barra, un fundamentalista religioso de pésima hermenéutica constitucional), no encontramos que la inclusión de esta cláusula altere el principio receptado en el derecho internacional de los derechos humanos (vgr:: Pacto de San José de Costa Rica, artículo $4^{\circ}$, párrafo 1) que consagra el derecho a la vida "en general, a partir de la concepción”, y al cual la reforma de 1994 otorgó nivel supralegislativo en el inciso 22 del artículo 75 de la Ley Fundamental. Además, no caben dudas que este tema -quizás, junto con la eutanasia, uno de los de mayor relevancia iusfilosófica- sólo puede ser analizado a la luz de lo que Bidart Campos llama el "bloque de constitucionalidad federal", respetando así la supremacía del artículo 31 de la Constitución Nacional.

La introducción de la "perspectiva de género" que prevé el artículo $38^{\circ}$ es una conquista del movimiento feminista que pone a esta Constitución en la avanzada del derecho comparado. Las constituyentes mujeres lucharon en el seno de la Convención por imponer lo que denominaron "lenguaje no sexista”, y así encontramos un capítulo dedicado a los niños, niñas y adolescentes. Queremos ser categóricos en este sentido: así como valoramos como muy positivo el perfil antidiscriminatorio del texto constitucional, esta especial definición terminológica nos parece absurda en todo sentido. En lo 
sustancial, aplaudimos la previsión de las medidas de acción positiva incluidas en este capítulo décimo, así como en la problemática juvenil y de la tercera edad (capítulos undécimo y duodécimo, respectivamente). Asimismo, la novedad de dedicar una cláusula específica a las personas con necesidades especiales (artículo 42\%), impone a las autoridades de la Ciudad la elaboración de políticas públicas que incluyan solidariamente esta perspectiva, lo cual consideramos un hecho por demás auspicioso (por ejemplo, la previsión de un cupo del 5\% en el empleo público prevista en el artículo 43\%).

Los 3 artículos que integran el capítulo sobre trabajo y seguridad social son una bocanada de aire fresco en momentos en que estas ramas del derecho son cuestionadas hasta en su propia autonomía por ideologías reaccionarias. Su contenido servirá, sin lugar a dudas, para elaborar líneas de acción a favor del empleo y de las condiciones dignas del trabajador, con los principios tuitivos que históricamente motivaron al derecho del trabajo (último párrafo del artículo 43으. Es un signo de madurez republicana que aplaudimos el rechazo a los regímenes de privilegio de la seguridad social que establece el artículo $44^{\circ}$. La creación del Consejo Económico y Social, organismo con iniciativa parlamentaria (lo cual fue olvidado en la mención del artículo $85^{\circ}$ para la sanción de las leyes) y representación de los sectores productivos, llena un vacío que a nivel nacional no pudo cubrir la Convención de Santa Fe en 1994 por desacuerdos políticos entre los distintos bloques partidarios.

Los consumidores y usuarios de bienes y servicios tienen prevista una garantía, "en su relación de consumo", contra la distorsión de los mercados y el control de los monopolios que los afecten. El artículo $46^{\circ}$ que integra el capítulo decimoquinto sigue las Directrices que en esta materia trazó la Asamblea General de las Naciones Unidas en 1985, las que sirvieron de antecedente al momento de redactar el nuevo artículo 42 de la Constitución Nacional. La participación necesaria de los consumidores y usuarios de servicios públicos está prevista en el Ente Único Regulador creado por los artículos $138^{\circ}$ y $139^{\circ}$, pero la misma no reviste operatividad inmediata hasta la sanción de la ley reglamentaria, según lo establece la cláusula transitoria vigesimosegunda.

El debate del capítulo decimosexto, referido a la comunicación, estuvo teñido por la disputa con el gobierno nacional y su proyecto de privatización de la frecuencia de la radio municipal, lo cual originó una presentación judicial de las autoridades de la Ciudad apenas asumidas el 6 de Agosto de 1996. La gestión de los servicios de radiodifusión y teledistribución será llevada adelante por un ente autárquico que la Legislatura deberá reglamentar, garantizando y estimulando la participación social, tal cual lo exige el último párrafo del artículo $47^{\circ}$.

En materia de economía, finanzas y presupuesto, la Constitución de la Ciudad de Buenos Aires fija como política de Estado que "la actividad económica sirva al desarrollo de la persona y se sustente en la justicia social” (artículo 48º), marcando así un horizonte humanista que compartimos plenamente. El contenido del capítulo decimoséptimo constituye uno de los aspectos más ponderables del texto constitucional, por cuanto se introducen principios modernos y progresistas en la materia. Es mucho lo que ha evolucionado la doctrina en estas cuestiones, que el constitucionalismo liberal casi no consideraba en profundidad. Autores 
como Rodolfo Spisso y Alberto Ricardo Dalla Vía han enriquecido en los últimos años la bibliografía del derecho constitucional económico. Por ello, señalaremos aquí sólo algunos puntos remarcables.

En primer término, estimamos un acierto en la técnica legislativa utilizada el de separar la defensa de la competencia de la normativa específica sobre los derechos de los usuarios y consumidores. La reforma de 1994 incluyó ambas cuestiones en el artículo 41, pero no debe olvidarse que el constituyente nacional se vio limitado por el mandato de la Ley No 24.309 que habilitó el tema para ser incluido en un solo artículo del capítulo de nuevos derechos y garantías. El constituyente local, por su parte, pudo actuar sin este corsé, e incluyó este principio en el artículo $48^{\circ}$ ya mencionado, junto con la promoción de las pequeñas y medianas empresas, los emprendimientos cooperativos, mutuales y "otras formas de economía social". El artículo $49^{\circ}$ subraya dicho perfil productivo.

La reserva hecha por el constituyente en el artículo $50^{\circ}$ para la Ciudad de regular, administrar y explotar los juegos de azar, destreza y apuestas mutuas, y de destinar lo producido a la asistencia y al desarrollo social, será otro motivo de conflicto con el gobierno nacional, tal cual lo remarcamos al analizar el artículo 9o, inciso 10. Hay que tener presente en este punto, también, lo establecido en la cláusula transitoria decimonovena. Por su parte, el articulo 510 avanza en la definición de principios tributarios que erradicarán los aspectos más regresivos de la materia impositiva a nivel federal.

Dos aspectos destacables en materia presupuestaria - el carácter participativo establecido por el artículo $51^{\circ}$, así como la prohibición de los gastos reservados incluida en el artículo $52^{\circ}$-, afirman la voluntad democrática y republicana del constituyente. En similar sentido, los dos últimos artículos del capítulo, referidos al tema financiero, completan el esbozo de los instrumentos para una gestión económica eficaz y transparente.

La función pública entendida como un servicio al conjunto de la sociedad es el eje de la normativa del capítulo decimoctavo. Así, los funcionarios de la administración pública de la Ciudad no podrán excederse en sus facultades legales a riesgo de asumir la responsabilidad por los daños ocasionados. La obligatoriedad de presentación de la declaración jurada de bienes al momento de asumir y al cesar en el cargo (artículo 56) y la imposibilidad de designar procesados por delitos dolosos, así como la separación de los condenados por los mismos tipos penales contra la administración pública (artículo 570) son otras plausibles muestras de las bondades de la Constitución de la Ciudad Autónoma de Buenos Aires. 


\section{LIBRO SEGUNDO. GOBIERNO DE LA CIUDAD}

\section{- $\quad$ TÍTULO PRIMERO. REFORMA CONSTITUCIONAL}

El tema del poder constituyente en el trazado de cualquier carta constitucional es el más delicado desde el punto de vista institucional. La toma de posición a favor de su rigidez o flexibilidad, y de los mecanismos de reforma consiguientes, exige gran prudencia al momento de incorporar una norma como la de nuestro artículo 30 de la Ley Fundamental. Y es indudable que este antecedente y la historia de las reformas en este mas de siglo y medio desde 1853 a la fecha -amén de los aportes del constitucionalismo provincial y comparado-, fueron muy tenidos en cuenta al momento de redactar el artículo $60^{\circ}$ a la cabeza de la parte orgánica de la Constitución de la Ciudad de Buenos Aires.

Todos las discusiones doctrinarias que se dieron con motivo fundamentalmente de las reformas nacionales de 1949, 1957 y 1994 fueron salvados por el constituyente local con claridad e inteligencia, a fin de evitar gratuitas discusiones en el futuro. Así, la necesidad de la reforma total o parcial deberá ser declarada por una ley en sentido formal, la cual exige una mayoría especial del cuerpo; dicha ley es la expresión única para dejar habilitado al ejercicio del poder constituyente derivado, por lo cual no podrá ser vetada por el Poder Ejecutivo. Esta ratificación de las facultades del Poder Legislativo no hace sino dejar en claro cuál es la fuente de legitimidad en esta espinosa cuestión, dejando así a la decisión excluida -según pacífica doctrina- del control de constitucionalidad posterior por parte del Poder Judicial, salvo la falta de cumplimiento de las exigencias establecidas en el capítulo referido a la sanción de las leyes. La expresa y taxativa indicación de las normas objeto de reforma, así como el plazo de duración del funcionamiento del órgano convocado "ad hoc" y de la fecha de elección de los representantes constituyentes, son requisitos que agregan previsibilidad y seguridad jurídica al siempre político proceso de reforma constitucional. Es, pues -como quiere Alberto A. Spota-, una forma razonada y razonable de "juridizar lo político", objetivo que a la larga es la "ultima ratio" de todo el derecho constitucional.

\section{- TÍTULO SEGUNDO. DERECHOS POLÍTICOS Y PARTICIPACIÓN CIU- DADANA}

El presente título agrega algunas particularidades a la normativa constitucional federal introducida en la reforma de 1994, a través de sus artículos 37 a 40 inclusive. Así, el artículo $61^{\circ}$ manda sancionar una ley que limite los gastos y la duración de las campañas electorales, e impone la obligatoriedad de la abstención del gobierno local de turno de realizar propaganda institucional que tienda a inducir el voto. Por su parte, el artículo $62^{\circ}$ agrega la característica de "no acumulativo" al sufragio -que no pudo ser incluida en ocasión de los debates en la Convención en Santa Fe- cerrando así definitivamente el camino a cualquier intento de imponer la denominada "ley de lemas" en el distrito. Este punto es trascendente para evitar distorsiones al sistema electoral en razón de circunstanciales conveniencias partidarias, toda vez que el mecanismo ha sido muy criticado en los distritos donde se impuso, y hoy 
en día se revisa a la luz de la abolición del mismo en el propio país de origen -la República Oriental del Uruguay-, el que lo abrogó por medio de un plebiscito constitucional llevado a cabo el 8 de Diciembre de 1996.

La citada norma contiene, también, el principio de igualdad para el ejercicio de los derechos políticos a los extranjeros residentes en la Ciudad. Si bien esta equiparación con los ciudadanos argentinos empadronados en este distrito queda sujeta a los términos que establezca la ley, adelantamos desde ya que -en nuestra opinión- la misma deberá ser en sentido estricto, a fin de no colisionar con el juego armónico de los artículos 14 y 20 de nuestra Carta Magna. La generosidad y la amplitud de su preámbulo -que convoca "a todos los hombres del mundo que quieran habitar el suelo argentino" - fue redoblada aquí por el constituyente porteño, recogiendo así la pluralidad y la diversidad de su población.

El régimen de audiencias públicas contenido en el artículo $63^{\circ}$ es un signo claro del deseo de la Convención de dotar a la ciudadanía porteña de los más eficientes instrumentos de participación democrática. El carácter vinculante de la convocatoria cuando la iniciativa cuente con un apoyo suficiente del electorado, y la presencia inexcusable de los funcionarios competentes en todos los supuestos, son dos elementos que perfeccionan la figura tomada principalmente del derecho anglosajón.

Los mecanismos de democracia semidirecta fueron ya incorporados a nivel federal por la reforma de 1994, pero la Constitución de la Ciudad de Buenos Aires afianza sus aspectos procedimentales de manera indubitable. La iniciativa popular -artículo $64^{\circ}-$, el referéndum -artículo $65^{\circ}$ - y la consulta popular —artículo $66^{\circ}$ - son prolijamente precisados; por su parte, la introducción de la revocatoria de mandatos o "recall" (una figura que nació del derecho municipal) es una de las más valientes muestras de respeto a la soberanía popular. La descentralización en comunas -que el propio constituyente aplazó hasta el año 2000 y hoy sigue pendiente de implementación efectiva- completará el marco instrumental para profundizar el ejercicio de los derechos ciudadanos de los todos los habitantes de la Ciudad.

\section{- TÍTULO TERCERO. PODER LEGISLATIVO}

\section{CAPÍTULO PRIMERO - ORGANIZACIÓN Y FUNCIONAMIENTO}

La definición del perfil de la estructura de gobierno de la Ciudad fue objeto de largos debates y negociaciones políticas. El bloque mayoritario en la Convención -el FREPASO- trató de imponer un régimen de contenido más cercano al parlamentarismo, mientras que la primera minoría -la Unión Cívica Radical - pretendió atenuar estos rasgos, a la vez que postergar la entrada en vigencia de la descentralización comunal por cinco años. Estas diferencias aparecieron como las caras visibles de ambas posiciones políticas durante las primeras instancias de la Convención. Recién cuando existió el consenso político necesario -que le significó al Vicejefe de Gobierno ceder el manejo administrativo y presupuestario de la Legislatura, recogido en los artículos $71^{\circ}$ y $99^{\circ}$-pudo destrabarse la labor constituyente, con la firma del llamado "Pacto de Palermo". Resultó paradójico que los mismos dirigentes 
políticos que se encargaron de estigmatizar la firma del denominado "Pacto de Olivos" firmado en Diciembre de 1993 -que habilitó el camino de la reforma nacional de 1994-, tuvieran que apelar a la transacción y al "toma y daca" para allanar el camino del consenso, herramienta fundamental de todo proceso constituyente que no acepte la imposición sino el diálogo constructivo y maduro a la hora de elaborar las reglas de juego de un sistema democrático genuino.

En definitiva, el Poder Legislativo de la Ciudad será ejercido por una Legislatura de 60 miembros electos por voto directo no acumulativo conforme al sistema proporcional, con un mandato de 4 años de duración. Hay que tener presente que para la primera elección de legisladores, la Ciudad de Buenos Aires se constituyó en distrito único por mandato de la cláusula transitoria quinta de la Constitución, hasta tanto la Legislatura estableciera el régimen electoral con el voto de una mayoría especial (dos tercios de sus miembros). Esta primera integración legislativa duró, por única vez, desde el día de la incorporación de sus miembros hasta el día del cese del mandato del Jefe de Gobierno (cláusula transitoria sexta), y fue esa primera Legislatura la que estableció el sistema que garantizó su renovación en forma parcial a partir de la segunda Legislatura, inclusive, para dar cumplimiento al último párrafo del artículo 69\%. Esta misma norma establece, también, la posibilidad de reelección transcurrido el intervalo de 4 ańos. El juego de esta restricción con lo establecido en el artículo $98^{\circ}$ para el Jefe y el Vicejefe de Gobierno - con una postura prudentemente reeleccionista-, genera un desequilibrio entre ambos poderes políticos.

Entre los requisitos para ser diputado que impone el artículo $70^{\circ}$, el inciso 3 establece "ser mayor de edad”. Esto resultó ser un instrumento adecuado para la participación política de la juventud, que tuvo antecedentes en el derecho municipal para la integración de los concejos deliberantes locales en ciudades de menor envergadura que Buenos Aires. Las inhabilidades e incompatibilidades introducidas en los artículos $72^{\circ}$ y $73^{\circ}$ completan un cuadro novedoso que ponderamos positivamente.

Otra cuestión que trajo gran polémica y presiones políticas fue la decisión de la Convención de limitar el presupuesto de la Legislatura al uno y medio por ciento del presupuesto total de la Ciudad para el primer mandato, tope que fue mantenido con mayoría calificada con su segunda integración y permanece inalterado a la fecha. Si a esta cláusula artículo $75^{\circ}$ - le sumamos la desaparición del Concejo Deliberante a partir del 10 de Diciembre de 1997, la fijación de una remuneración que no podrá ser superior a la percibe el Jefe de Gobierno, y un régimen de designaciones de personal como el establecido en el artículo $76^{\circ}$, estamos ante una respuesta positiva frente a las legítimas expectativas a favor de la recuperación de la confianza y respeto de la ciudadanía para con sus instituciones fundamentales.

Pero estos no fueron los únicos aspectos del derecho parlamentario que recogió la Constitución: los artículos $78^{\circ}$ y $79^{\circ}$ fijan un régimen de prerrogativas y disciplinario que constituye lo más actualizado en la materia. La claridad y precisión del texto que señala que "la inmunidad de arresto no implica la de proceso, ni impide la coerción dispuesta por juez competente para la realización de los actos procesales indispensables para su avance”, así como la posibilidad de levantar dicha inmunidad 
ante requerimiento judicial -con mayoría especial- o a pedido del diputado involucrado -con mayoría simple- actualiza esta siempre polémica cuestión a la luz de la práctica parlamentaria de los últimos años, y transparenta así un procedimiento de naturaleza típicamente política, en la cual la Legislatura "es juez exclusivo de los derechos y títulos de sus miembros" (primer párrafo del artículo 770), con el manifiesto objetivo de resguardar la labor parlamentaria a la vez que alejar la presunción de que la misma excede la inmunidad en el ejercicio de sus tareas para convertirse en la impunidad de sus miembros ante los ojos de la opinión pública.

\section{CAPÍTULO SEGUNDO - ATRIBUCIONES}

Los 27 incisos que integran el artículo 80 de la Constitución de la Ciudad de Buenos Aires determinan las atribuciones de la Legislatura, cuyas decisiones deberán ser sancionadas con la mayoría simple que acostumbra la práctica parlamentaria. Entre sus facultades, este órgano está investido para dictar una ley de puertos de la Ciudad (inciso 6), regular los juegos de azar, destreza y apuestas mutuas (inciso 19) y la organización y funcionamiento de los registros de la Propiedad Inmueble, de Personas Jurídicas y del Estado Civil y Capacidad de las Personas (inciso 25), en abierta confrontación con la Ley de Garantías del Estado Nacional. Cabe aquí el mismo comentario que hicimos al analizar esta cuestión en cada supuesto en particular. Por lo demás, es muy saludable desde el punto de vista procedimental el agrupamiento efectuado en esta norma, que es diferente del realizado en el artículo $81^{\circ}$-que requieren para su sanción mayoría absoluta- y en el artículo $82^{\circ}$-en que se exige mayoría especial-, por cuanto esta diferenciación aclara uno de las mayores confusiones introducidas en la reforma de 1994, al establecer anárquicamente distintas mayorías parlamentarias en el articulado de la Ley Fundamental.

Encontramos una contradicción entre la facultad de "conservar los organismos de seguridad social para los empleados públicos y los profesionales” que prevé el último párrafo del artículo 125 de la Constitución Nacional -el cual de acuerdo al punto f) del inciso 2 del artículo $80^{\circ}$ requiere mayoría simple- y la de "crear" dichos organismos -el cual de acuerdo al inciso 5 del artículo $81^{\circ}$ requiere mayoría absoluta-; en igual sentido, vemos idéntica contradicción entre la facultad de "regular la adquisición de inmuebles" por mayoría simple (inciso 9 del artículo 80), y la "disposición de bienes inmuebles" que prevé con mayoría especial el inciso 4 del artículo $82^{\circ}$. Pero estas observaciones se ven altamente compensadas por la terminante prohibición de delegación legislativa incluida en el artículo $84^{\circ}$ de esta Constitución, muy superior por su certeza a la ambigua disposición del artículo 76 de la Ley Fundamental.

\section{CAPÍTULO TERCERO - SANCIÓN DE LAS LEYES}

Ya hemos señalado la omisión del Consejo Económico y Social entre quienes gozan de iniciativa legislativa al comentar dicho instituto (artículo 45). Más allá de esta pequeña omisión -que podrá ser salvada por la facultad prevista en la cláusula transitoria vigésimo cuarta-, este capítulo merece varios 
comentarios positivos, sobre todo a la luz del constitucionalismo comparado y la experiencia de la reforma de 1994.

En primer lugar, el artículo $86^{\circ}$ establece la promulgación tácita en caso de no existir veto a una ley por parte del Poder Ejecutivo dentro de los diez días hábiles a partir de su recepción, y la obligatoriedad de publicación de la ley dentro de similar plazo a partir de su promulgación, facultando a la Legislatura a hacerlo en caso de omisión por parte del Poder Ejecutivo. Esta salvedad -que puede parecer, en principio, un exceso reglamentarista- es de suma utilidad para posibles situaciones de conflicto entre ambos poderes políticos.

En segundo lugar, el juego armónico de los artículos $87^{\circ}$ y $88^{\circ}$ en materia de veto erradica en el ámbito de la Ciudad una tristemente célebre práctica institucional: la promulgación parcial de las leyes. Aquí también se superan las ambigüedades de la reforma de 1994, que no pudo con la inclusión del concepto de "autonomía legislativa" en el artículo 80 de la Ley Fundamental, poner freno a los excesos en este sentido del actual gobierno nacional. El procedimiento mencionado en ambas normas se ve facilitado, además, por ser el local un Poder Legislativo unicameral.

Pero la más interesante innovación de este capítulo está dada por el mecanismo de doble lectura en determinadas materias (artículo 89 ${ }^{\circ}$ y con precisos requisitos (artículo $90^{\circ}$ ) que el constituyente tomó del derecho municipal, como bien señala Antonio María Hernández. Este instrumento de participación ciudadana servirá, sin lugar a dudas, para otorgar transparencia al proceso de formación legislativa en cuestiones que hacen a la vida cotidiana de la sociedad, y es terminante la Constitución al excluir cualquier hipótesis que algún órgano de gobierno pueda aducir para hacerse el distraído y desconocer este trámite.

Por último, en materia de decretos de necesidad y urgencia, el constituyente local invirtió los términos impuestos en la reforma de 1994 a nivel federal, y siguió en el artículo $91^{\circ}$-y su concordante artículo $103^{\circ}$ - el sano criterio de exigir su ratificación legislativa expresa como condición para su vigencia, y no el cuestionado régimen del inciso 3 del artículo 99 de la Constitución Nacional, con lo cual los principios republicanos en general, y el de división de poderes en particular, vuelven a estar resguardados prudentemente.

\section{CAPÍTULO CUARTO - JUICIO POLÍTICO}

Este mecanismo de control político está reservado a situaciones taxativas de excepción para los principales responsables del gobierno de la Ciudad -fuera del Poder Legislativo-, siguiendo en gran medida el modelo de la Constitución de 1853/60, hoy incluido en sus artículos 53, 59 y 60. Sin embargo, podemos señalar algunas particularidades que enriquecen el texto de los artículos $92^{\circ}$ a $94^{\circ}$ que integran este capítulo. 
En efecto, aquí se amplía la nómina de quienes pueden ser pasibles de juicio político -en comparación con la Ley Fundamental - a los miembros del Consejo de la Magistratura, al Fiscal General, al Defensor General, al Asesor General de Incapaces, al Defensor del Pueblo y “a los demás funcionarios que esta Constitución establece” (artículo 92º). El mecanismo previsto en el artículo $93^{\circ}$ al dividir la Legislatura unicameral en una sala acusadora y otra de juzgamiento, sigue una larga tradición del derecho público provincial. Pero el artículo $94^{\circ}$ introduce dos precisiones que evitarán largas y estériles disputas doctrinarias en el futuro: la suspensión del acusado en sus funciones, sin goce de haberes, durante el trámite del juicio, por un lado, y el supuesto de falta de resolución del mismo en los cuatro meses posteriores a dicha suspensión, "en cuyo caso se considera absuelto al acusado, sin poder ser sometido a un nuevo juicio político por identidad de hechos". Estas novedades hacen más eficaz este mecanismo de control político, que algún estudioso del derecho constitucional llegó a definir como "una pieza de museo".

\section{- TÍTULO CUARTO. PODER EJECUTIVO}

\section{CAPÍTULO PRIMERO - TITULARIDAD}

$\mathrm{Al}$ analizar la arquitectura del Poder Ejecutivo de la Constitución de la Ciudad de Buenos Aires, caben las consideraciones que efectuáramos al introducir el análisis del Poder Legislativo, en cuanto a la definición del perfil general de la estructura gubernativa. En definitiva, el resultado del ya comentado "Pacto de Palermo" arrojó un régimen más cercano a la tradición presidencialista, si bien con ciertas atenuaciones.

En definitiva, la titularidad del Poder Ejecutivo de la Ciudad Autónoma de Buenos Aires es unipersonal -el artículo $95^{\circ}$ utiliza para su denominación una vez más el lenguaje "no sexista"- el cual es elegido en forma conjunta y directa con el Vicejefe, por fórmula completa y mayoría absoluta en distrito único, previendo el artículo $96^{\circ}$ la figura del "ballotage" según el modelo francés, o sea con mayoría absoluta de los votos emitidos, excluidos los en blanco y los nulos. Los requisitos exigidos por el artículo $97^{\circ}$ son prácticamente idénticos a los que establece la Ley Fundamental en su artículo 89 para ser Presidente de la República. En cambio, el artículo $98^{\circ}$ mejora en técnica legislativa a los artículos 90 a 93 de la Ley Fundamental, al abrir la posibilidad de remoción por el mecanismo de la revocatoria popular y precisar su remuneración. No compartimos la excepción de las tareas docentes a la incompatibilidad de ejercer otro cargo público o profesión alguna: nos inclinamos por la incompatibilidad absoluta mientras se desempeñen en los cargos. En materia de duración del mandato, la cláusula decimoprimera no deja lugar a dudas en cuanto a la posibilidad de una sola reelección para el Jefe de Gobierno. Asimismo, la cláusula transitoria cuarta ya estableció la facultad, "por única vez", de la primera Legislatura de modificar la duración del próximo Jefe de Gobierno, el de su Vicejefe y el de los legisladores del próximo periodo, con el fin de hacer coincidir las elecciones de autoridades de la Ciudad con las autoridades nacionales. Esta decisión se adoptó dentro del primer ańo desde su instalación, por medio de una ley sancionada con mayoría especial (2/3 del total de sus miembros). 
La figura del Vicejefe quedó bastante disminuida luego del acuerdo político ya referido, limitando su importancia a los supuestos de acefalía que prevé el artículo $99^{\circ}$ en su primer párrafo, pues el segundo párrafo de dicha norma -en concordancia con el artículo $7 l^{\text {o- }}$ señala que "corresponde al Vicepresidente Primero de la Legislatura tener a su cargo la administración y coordinación del cuerpo". Más allá de las necesidades de facilitar la labor constituyente al momento de la firma de dicho acuerdo, no vemos la utilidad de esta división de atribuciones, que desnaturaliza en parte la institucionalidad de la Presidencia de la Legislatura. Una consecuencia de esta metamorfosis de la naturaleza jurídica del Vicejefe de Gobierno es que hoy ejerce la función de un ministro, en abierta violación al principio de división de poderes.

\section{CAPÍTULO SEGUNDO - GABINETE}

La figura del gabinete que introduce este capítulo puede inducir, en principio, la idea que el Constituyente tuvo en cuenta los modelos parlamentaristas al estilo inglés o, con menor intensidad, los de España o Italia. Pero apenas descubrimos el texto del artículo $100^{\circ}$ de la Constitución de la Ciudad, vemos que estos ministros no varían en cuanto a sus facultades de las que les atribuye la Ley Fundamental en sus artículos 102 a 107 a sus homónimos a nivel federal. Si bien no está incluida a nivel local el instituto del Jefe de Gabinete que incorporó la reforma de 1994, el artículo 104º le atribuye específicamente al Jefe de Gobierno de la Ciudad la facultad de nombrar un Ministro Coordinador (inciso 4), a fin de que éste coordine y supervise las actividades de los restantes miembros del Gabinete, y presida los acuerdos y sesiones en ausencia del titular del Poder Ejecutivo, y ha sido ésta la práctica institucional en los sucesivos gobiernos locales.

\section{CAPÍTULO TERCERO - ATRIBUCIONES Y DEBERES}

El presente capítulo es, a nuestro entender, el de mejor técnica legislativa de toda la Constitución de la Ciudad. Si bien algunas de las atribuciones del Jefe de Gobierno contenidas en el artículo 104 o colisionan con la Ley de Garantías del Estado Nacional (v.gr.: incisos 20 y 31), el juego armónico del articulado traza un marco preciso de facultades, a las que se deben agregar los deberes del artículo $105^{\circ}$. Es muy importante tener presente que el constituyente tuvo en sus miras la voluntad de presentar a la figura del Jefe de Gobierno como el de un gobernador provincial -incluso lo llama así en algunas normas-, lo cual se subraya en el inciso 12 del mencionado artículo $105^{\circ}$ al imponerle la obligación de "hacer cumplir, como agente natural del Gobierno Federal, la Constitución y las leyes nacionales", usando una analogía a lo previsto por el artículo 128 de la Ley Fundamental.

\section{- TÍTULO QUINTO - PODER JUDICIAL}

\section{CAPÍTULO PRIMERO - DISPOSICIONES GENERALES}

La integración material del Poder Judicial local es la gran asignatura pendiente de desarrollo constitucional para la Ciudad de Buenos Aires. Junto con el tema seguridad, fueron los dos grandes obstá- 
culos que se le impusieron a la autonomía plena consagrada en el artículo 129 de la Constitución Nacional. A nadie escapa que un sistema institucional que no cuente con esta rama es un sistema rengo. La Convención desafió esta vocación reduccionista con el armado de una ingeniería constitucional de gran factura, ratificada posteriormente por una Ley Orgánica en la materia.

El artículo $106^{\circ}$ establece que "corresponde al Poder Judicial de la Ciudad el conocimiento y decisión de todas las causas que versen sobre puntos regidos por esta Constitución, por los convenios que celebre la Ciudad, por los códigos de fondo y por las leyes y normas nacionales", manteniendo un perfil propio de los órganos judiciales provinciales, en la buena tradición del federalismo argentino. Le agrega dos elementos: la facultad de organizar la mediación voluntaria en correspondencia con la Legislatura, y la de establecer el juicio por jurados (artículo 81을 inciso 2).

Es fundamental la definición acerca de cuáles son los organismos que lo integran: el Tribunal Superior de Justicia y los demás tribunales inferiores que establezca la ley, junto al Consejo de la Magistratura y el Ministerio Público (capítulos tercero y quinto del presente Título). Se superan así los ricos pero excesivamente teóricos debates doctrinarios acerca de la naturaleza jurídica de estos últimos, al ubicarlos indubitablemente en la órbita del Poder Judicial de la Ciudad.

A la garantía de división de poderes que la primera parte del artículo $108^{\circ}$ impone con idéntico alcance que el artículo 109 de la Constitución Nacional, la misma norma le agrega en su segunda parte un mandato novedoso: cada uno de los poderes "es responsable en el ámbito de su competencia, de dotar al Poder Judicial de los recursos necesarios para garantizar el acceso a la justicia y la resolución de los conflictos en tiempo razonable y a un costo que no implique privación de justicia”.

Completando este capítulo introductorio, los artículos $109^{\circ}$ y $110^{\circ}$ precisan en las cuestiones del juramento y las retribuciones de los miembros del Poder Judicial de la Ciudad. Hay que relacionar ambas normas con las cláusulas transitorias decimoquinta, que establece que los integrantes del primer Tribunal Superior de Justicia -designados en comisión- presten juramento ante el Jefe de Gobierno y, con su primera integración definitiva, ante el Presidente del cuerpo, y la decimosexta, que prevé una retribución para dicho Presidente equivalente al 90\% de la que perciba "por todo concepto" el Presidente de la Corte Suprema de Justicia de la Nación, hasta que la Legislatura estableció el régimen definitivo en este punto.

\section{CAPÍTULO SEGUNDO - TRIBUNAL SUPERIOR DE JUSTICIA}

La integración del Tribunal Superior de Justicia y los requisitos exigidos para ser miembro del mismo no se apartan de 1 os lineamientos comparados de similares organismos. Podemos destacar la plausible novedad de exigir que no todos los miembros del mismo sean de igual sexo (artículo 111\%), y la precisión del artículo $112^{\circ}$ respecto a la antigüedad como abogado -8 años de graduado, y no de ejercicio profesional como exige la Ley Fundamental-. Pero donde el Tribunal Superior adquiere un perfil propio muy definido es en la delimitación de competencias fijada en el artículo $113^{\circ}$ de la Constitución de la Ciudad. 
Analizaremos sucintamente los 6 incisos de la citada norma. El primero prevé el supuesto de conflictos entre los poderes de la Ciudad -que el Tribunal Superior entenderá en forma originaria y exclusiva-, habilitando así un ámbito de resolución institucional que puede aportar razonabilidad y prudencia en favor del resguardo del sistema político adoptado por esta Constitución. El inciso 5 establece una instancia ordinaria de apelación "en las causas en que la Ciudad sea parte" con montos a determinar por ley reglamentaria. Sin embargo, la "perla" que motivará una fuente inagotable de comentarios es la acción declarativa de inconstitucionalidad prevista en el inciso 2. Dicha cláusula señala que este órgano se expedirá originaria y exclusivamente en esos supuestos contra la validez de leyes, decretos y cualquier otra norma de carácter general emanada de las autoridades de la Ciudad, "contrarias a la Constitución Nacional o a esta Constitución", con el efecto derogatorio de dicha resolución. Esta pérdida de vigencia sólo podrá ser evitada en caso de que la ley cuestionada sea ratificada por la Legislatura dentro de los tres meses de la sentencia declarativa, por medio de una mayoría especial (2/3 de los miembros presentes), pero la norma aclara que, aún en dicho supuesto, no se alteran sus efectos en el caso concreto, ni se impide el posterior control difuso de constitucionalidad ejercido por todos los jueces y por el mismo Tribunal Superior.

Esta acción declarativa de inconstitucionalidad enriquece el catálogo de instrumentos de control, sin afectar el sistema federal que la jurisprudencia de la Corte Suprema de Justicia de la Nación ha ratificado desde sus orígenes siguiendo en gran medida el modelo norteamericano desde el famoso caso "Marbury vs. Madison" (1801). A esta acción debemos agregar que, por vía de recurso de inconstitucionalidad, el inciso 3 otorga competencia al Tribunal Superior para entender en todos los casos que versen sobre "la interpretación o aplicación de normas contenidas en la Constitución Nacional o en esta Constitución”. Asimismo, la competencia de este órgano se extiende a los casos de privación, denegación o retardo injustificado de justicia (inciso 4), con lo cual se abre aún más el abanico de mecanismos que el ciudadano porteño tiene en sus manos para hacer efectiva la garantía de acceso a la justicia ya analizada en el artículo $108^{\circ}$.

También cabe señalar que si bien la competencia en materia electoral y de partidos políticos es originaria -según lo establecido en el inciso 6-, la misma norma prevé la posibilidad de creación de un cuerpo específico para dicha materia, reservándose el Tribunal Superior su actuación por vía de apelación. Por último, el artículo $114^{\circ}$ faculta a este órgano a dictar su propio reglamento interno, a nombrar y remover a sus empleados, y a "proyectar y ejecutar su presupuesto", con lo cual se ratifica de manera indubitable su condición de cabeza del Poder Judicial de la Ciudad.

\section{CAPÍTULO TERCERO - CONSEJO DE LA MAGISTRATURA}

El instituto contemplado en este capítulo ya fue receptada en la reforma de 1994, que lo incluyó en el nuevo artículo 114 de la Ley Fundamental. En ese entonces, la misma fue objeto de duras disputas en su redacción final, por cuanto si bien estaba prevista en el acuerdo político que posibilitó la sanción de la Ley No 24.309. Esta discusión fue saldada en la Convención de Santa Fe con la redacción de 
una cláusula que deja abiertos muchos interrogantes, los cuales son aún hoy objeto de debate parlamentario a fin de reglamentar el instituto con el objetivo que motivó su incorporación constitucional: fortalecer la independencia del Poder Judicial.

Esta experiencia fue muy tenida en cuenta por la Convención porteña, que buscó no dejar hilos sueltos en el tejido de la figura. En primer lugar, se fijó que el Consejo de la Magistratura forma parte del Poder Judicial de la Ciudad, alejando cuestionamientos con respecto a su naturaleza jurídica. Pero donde el constituyente fue muy prolijo es en la definición de la integración del organismo, sin caer en la ambigua mención del segundo párrafo del artículo $114^{\circ}$ de la Ley Fundamental -el "equilibrio" al que se debe procurar entre las distintas representaciones_- y fijando en nueve su composición, de acuerdo al mecanismo de tercios estamentarios -jueces, abogados, representantes de la Legislaturaque el mismo artículo $115^{\circ}$ prevé. La duración de los mandatos en cuatro años -no la vaga fórmula de la "periodicidad" que se impuso a nivel federal-, la equiparación en materia de incompatibilidades e inmunidades a los jueces, y el procedimiento de remoción por juicio político, son precisiones que otorgan mayor entidad a la institución.

En cuanto a sus funciones, el artículo $118^{\circ}$ señala la de seleccionar mediante concurso público de antecedentes y oposición a los candidatos, no sólo de los tribunales inferiores, sino también del Ministerio Público "que no tengan otra forma prevista por esta Constitución". Recordemos que la Legislatura designa a los jueces por acuerdo, según lo establecido por el inciso 24 del artículo 80 y $118^{\circ}$, pero que el Jefe de Gobierno propone a los miembros del Tribunal Superior de Justicia, al Fiscal General, al Defensor Oficial, y al Asesor Oficial de Incapaces, a tenor de lo establecido por los incisos 5 y 6 del artículo 104º La propuesta que efectúe el Consejo de la Magistratura a la Legislatura no tiene el impreciso contenido de las "ternas vinculantes" que similar inciso 2 del artículo 114 de la Ley Fundamental establece. Queda claro, también, que el nombramiento, la remoción y el régimen disciplinario de los funcionarios y empleados del Poder Judicial debe ser reglamentado por el propio Consejo, a través de un mecanismo de concurso con intervención de los jueces en todos los casos.

La facultad de recibir denuncias contra los jueces y los integrantes del Ministerio Público del inciso 7 de esta norma se complementa con la de decidir la apertura del procedimiento de remoción de magistrados del inciso 8, a fin de poder formular la acusación correspondiente ante el Jurado de Enjuiciamiento previsto en el capítulo quinto de este Título.

Todo este edificio institucional queda sujeto, en la práctica, a una ley especial que la Legislatura sancionó con el voto de la mayoría absoluta de la totalidad de sus miembros, por imperio del artículo $117^{\circ}$ de la Constitución. Hasta entonces, el Jefe de Gobierno pudo designar en comisión a los miembros y constituir el Tribunal Superior, los fueros contencioso administrativo y tributario, contravencional y de faltas -y hasta crear los tribunales que resulten necesarios -, así como el Ministerio Público, en virtud de la cláusula transitoria decimosegunda. 


\section{CAPÍTULO CUARTO - TRIBUNALES DE LA CIUDAD}

El artículo $118^{\circ}$ define el procedimiento de designación de los magistrados de los tribunales inferiores de la Ciudad. En concordancia con la facultad acordada por la Legislatura en el artículo 80², inciso 24, establece que se requiere una mayoría absoluta para concretar una propuesta del Consejo de la Magistratura. En el supuesto de rechazo -que puede efectuar en una sola oportunidad por cada vacante que se produzca-, se faculta al mencionado organismo a proponer un nuevo aspirante, sobre cuyas calidades la Legislatura debe pronunciarse dentro de los sesenta días hábiles (excluido el receso legislativo), pues en caso de silencio, se reputa aprobada la propuesta. Es muy auspicioso la obligatoriedad de la audiencia pública prevista por el artículo $120^{\circ}$, a fin de dar la máxima publicidad al acto de gobierno, tanto en la instancia de la Comisión competente como en la sesión propiamente dicha, y así deberá ser receptado el procedimiento en el reglamento que dicte oportunamente la Legislatura.

La exclusión de la actividad docente del régimen delas incompatibilidades para jueces y funcionarios judiciales prevista por el artículo $119^{\circ}$ está aquí justificada en virtud de las tareas a desarrollar, las cuales en ningún caso podrán comprometer la imparcialidad de sus decisiones.

\section{CAPÍTULO QUINTO - JURADO DE ENJUICIAMIENTO}

Al igual que el Consejo de la Magistratura, la figura del "jury de enjuiciamiento" fue recogida en la reforma de 1994, que la incluyó en el artículo $115^{\circ}$ de la Ley Fundamental, aún cuando su integración y régimen procesal fueron derivados a la norma que reglamenta ambos institutos a nivel federal. La Constitución de la Ciudad de Buenos Aires, en cambio, le dedica tres artículos específicos que no dejan estas cuestiones libradas a un posterior desarrollo legislativo, aprovechando aquí también la experiencia postconstituyente nacional. Los jueces que pueden ser removidos por este Jurado de Enjuiciamiento son los correspondientes a los tribunales inferiores, por cuanto a los miembros del Tribunal Superior les está reservado el mecanismo del juicio político previsto en los artículos $92^{\circ}$ a 94․ La integración de los nueve miembros (3 legisladores, 3 abogados y 3 jueces) del jurado de enjuiciamiento está prevista en el artículo $121^{\circ}$, reservándose la presidencia para el designado por el Tribunal Superior. Su selección por sorteo se efectúa de una lista de 24 según lo previsto por la misma norma. Su mandato es de 4 ańos. Cabe destacar que las causales de remoción son las que taxativamente enumera el artículo $122^{\circ}$.

Con respecto al régimen procedimental, el artículo $123^{\circ}$ supera en precisión el texto de la Constitución Nacional. En primer lugar, el plazo de 180 días que puede extenderse la suspensión en su cargo del magistrado acusado se reduce a 90 días, vencido el cual si no existiere decisión definitiva se ordenará archivar el expediente. En segundo término, se deja abierta la posibilidad de recurrir la decisión del Jurado en el supuesto de que la misma sea manifiestamente arbitraria. La destitución debe ser adoptada por 5 miembros del Jurado. Si bien el efecto del fallo se agota en esta remoción, le cabe al acusado la responsabilidad civil o penal en caso de que pudiere corresponderle, como muy bien señala la norma indicada. 


\section{CAPÍTULO SEXTO - MINISTERIO PÚBLICO}

El debate doctrinario que se dio a partir de la incorporación del artículo 120 a la Constitución Nacional en la reforma de 1994 giró en tomo a su naturaleza judicial o de órgano extrapoder. Algunos autores -Spota y Ricardo Haro, entre los más destacados- se niegan a reconocer la posibilidad de órganos extrapoder en el sistema constitucional argentino, como pretendieron visualizar en el debate en Santa Fe algunos constituyentes nacionales. Pero, más allá de esta discusión, el texto del artículo $124^{\circ}$ local que encabeza este capítulo es aquí definitorio, por cuanto le otorga al Ministerio Público autonomía funcional y autarquía "dentro del Poder Judicial", subrayando así la mención respectiva del artículo $107^{\circ}$ ya comentado. Creemos que la decisión del constituyente local es la acertada para fortalecer la independencia de dicho órgano, máxime cuando las posiciones administrativistas que desnaturalizan en este punto al instituto siguen siendo fuertes.

El Fiscal General, el Defensor General y el Asesor General de Incapaces -la norma vuelve a referirse a los mismos con un lenguaje "no sexista"- son propuestos para su designación por el Jefe de Gobierno (cfr.: inciso 6 del artículo 104), y es la Legislatura la que otorga el acuerdo correspondiente (cfr.: inciso 24 del artículo $80^{\circ}$ ), a fin de ejercer sus funciones ante el Tribunal Superior de Justicia. Las mismas están previstas en el artículo $125^{\circ}$, en cuyo inciso 3 se incluye la facultad de "dirigir la Policía Judicial", con los alcances que el Poder Legislativo le atribuya. El mandato de los tres es de 7 años, con una posibilidad de reelección pasado un periodo completo.

La equiparación de las cabezas del Ministerio Público a los miembros del Tribunal Superior que menciona el artículo $126^{\circ}$ en su primer párrafo, en cuanto a su designación y mecanismo de remoción, es de gran trascendencia a la hora de afirmar su carácter independiente. Para los restantes funcionarios del Ministerio Público, el tercer párrafo de la misma norma prevé las mismas inmunidades y limitaciones que los jueces de los tribunales inferiores, y su remoción sólo puede ser decidida por el Jurado de Enjuiciamiento, reemplazando los dos jueces ajenos al Tribunal Superior por dos funcionarios del Ministerio Público, seleccionados de una lista de 8, alterando "ad hoc" la integración prevista en el artículo $121^{\circ}$.

\section{- $\quad$ TÍTULO SEXTO. COMUNAS}

La cuestión de la descentralización comunal fue uno de los ejes de discusión de la campaña electoral de 1996, y las cuatro fuerzas políticas que finalmente integraron la Convención Constituyente llevaron entonces propuestas de avanzada. Pero una vez constituido el cuerpo, las posiciones fueron variando como elementos de negociación entre los partidos, principalmente a partir de la resistencia que las autoridades de la Ciudad electas el 30 de Junio de 1996 opusieron, al ver en su puesta en marcha inmediata una posible licuación de su poder de administración. Por ello, la cuestión recién pudo ser zanjada con el ya mencionado "Acuerdo de Palermo", dentro de un consenso global sobre la marcha de la Convención. Así es como hoy los 5 artículos que integran este título -uno de los de 
mejor factura legislativa- se encuentran bajo una especie de "paraguas", en virtud de lo establecido por la cláusula transitoria decimoséptima, que dejó virtualmente en suspenso el régimen hasta el año 2000. Con esta salvedad, analizamos a continuación el contenido de la normativa de fondo de los artículos $127^{\circ}$ a $131^{\circ}$.

Las comunas a las que se refiere el Título Sexto son "unidades de gestión política y administrativa con competencia territorial”, tal como define al inicio el artículo $127^{\circ}$. Su organización y competencia -"preservando la unidad política y presupuestaria y el interés general de la Ciudad y su Gobierno”serán establecidas por una ley que requiere mayoría especial, la cual debe establecer unidades territoriales descentralizadas, garantizando el equilibrio demográfico y considerando aspectos urbanísticos, económicos, sociales y culturales, según reza la misma norma. Entre las competencias que esta norma les asigna -4 en forma exclusiva y 6 en forma concurrente-, se destaca claramente la novedosa elaboración del llamado "presupuesto participativo", modelo tomado esencialmente de las experiencias comunales de Curitiba y Porto Alegre en Brasil.

Las precisiones contenidas en el artículo $129^{\circ}$, al señalar que la ley de presupuesto deberá establecer los criterios de asignación en función de indicadores objetivos de reparto, "basados en pautas funcionales y de equidad, en el marco de principios de redistribución y compensación de diferencias estructurales", armonizan los criterios de descentralización con las pautas ya analizadas en los artículos $52^{\circ}$ y $53^{\circ}$.

La elección de los 7 miembros que integrarán la Junta Comunal indicada en el artículo $130^{\circ}$ quedó suspendida por un plazo no menos de 4 ni mayor de 5 años (cláusula transitoria decimoséptima) debiendo en ese entonces adecuarse a lo que determinare la ley electoral y de partidos políticos. El mencionado organismo de gobierno cuenta con la asistencia de otro de tipo consultivo y honorario, con representación entidades vecinales, redes y otras formas de organización, según lo reglamentado por la Legislatura, por mandato de lo establecido en la parte final del artículo 131 .

\section{- TÍTULO SÉPTIMO. ÓRGANOS DE CONTROL}

\section{CAPÍTULO PRIMERO - DISPOSICIONES GENERALES}

La reforma de 1994 introdujo dos órganos de control con jerarquía constitucional, la Auditoría General de la Nación -artículo 85- y el Defensor del Pueblo -artículo 86- , ambos dentro de la esfera del Poder Legislativo, en armonía con el sistema de "pesos y contrapesos" que edifica la Ley Fundamental. El Ministerio Público incluido como una Sección Cuarta dentro de la parte orgánica de la Constitución Nacional apuntó, también, a fortalecer dichos controles como un órgano extrapoder, pero sin la misma suerte en la realidad postconstituyente nacional que los ya señalados. El constituyente local, por su parte, fue mucho más cuidadoso al elaborar el modelo de control -que el artículo $132^{\circ}$ califica de "integral e integrado, conforme a los principios de economía, eficacia y eficiencia"-, y utilizó los institutos de la Sindicatura General y la Procuración General junto a la Auditoría General y 
el Defensor del Pueblo, para comprender así la totalidad del control interno y externo del sector público. Le sumó, también, un novedoso Ente Único Regulador de los Servicios Públicos para completar el presente título, cuyas disposiciones generales integran dos reafirmaciones genuinamente republicanas: la obligatoriedad de la rendición de cuentas de los funcionarios sobre su gestión, y la creación de una base de datos para registrar todo acto de contenido patrimonial de monto relevante, al cual se asegura el acceso libre y gratuito de cualquier habitante de la Ciudad de Buenos Aires.

\section{CAPÍTULO SEGUNDO - SINDICATURA GENERAL}

El artículo $133^{\circ}$ establece la dependencia de la Sindicatura General de la Ciudad Autónoma de Buenos Aires dentro de la esfera del Poder Ejecutivo, si bien le otorga personería jurídica propia y autarquía administrativa y financiera. Su naturaleza está claramente definida en el cuarto párrafo de la norma, al señalar que es "el órgano rector de las normas de control interno", y su jerarquía se pone de relieve al equiparar a su titular -designado y removido por el Jefe de Gobierno- con la de un ministro. Sus facultades de supervisión del procedimiento y de fiscalización del cumplimiento y aplicación de las normas de control fueron resguardadas por la Legislatura al momento de sancionar la ley reglamentaria de la organización y funcionamiento de este instituto.

\section{CAPÍTULO TERCERO - PROCURACIÓN GENERAL}

El artículo $134^{\circ}$ define la naturaleza de este instituto en su primer párrafo, al señalar que la Procuración General representa a la Ciudad "en todo proceso en que se controviertan sus derechos o intereses”. Además de las funciones de patrocinio letrado, la norma precisa la de dictaminar sobre la legalidad de los actos administrativos, y la defensa de su patrimonio. La designación de su titular precisa de acuerdo de la Legislatura (cfr.: artículo 80, inciso 24"), no así la remoción, que está reservada al Jefe de Gobierno. Es auspicioso el requisito del concurso público de oposición y antecedentes para integrar el plantel de abogados de la Ciudad que prevé el último párrafo de la norma, a fin de resguardar lo más posible el nivel de excelencia de su composición.

\section{CAPÍTULO CUARTO - AUDITORIA GENERAL}

Las dos normas que integran el capítulo traen importantes precisiones con respecto al instituto incorporado por la Convención de Santa Fe a nivel federal y a la Ley No 24.156 que lo contempla a partir del artículo 116 y siguientes. En primer término, el ejercicio del control externo del sector público "en sus aspectos económicos, financieros, patrimoniales, de gestión y de legalidad" se ve ampliado a la verificación de la correcta aplicación de los recursos públicos que se hubiesen otorgado como aportes o subsidios, incluyendo la novedad -en este último punto- de alcanzar como sujeto pasivo de esta facultad a los partidos políticos del distrito. En segundo lugar, se garantiza el acceso irrestricto a todos los dictámenes del organismo por parte de cualquier ciudadano, favoreciendo así la publicidad de cada acto de gobierno. Pero la novedad más trascendente está en la autarquía financiera que el primer párrafo del artículo 135" le agrega a la funcional, dotando de mayor fortaleza a esta Auditoría 
General de la Ciudad con respecto a su similar nacional, lo cual se ve subrayado por su propia personería jurídica y la legitimación procesal que esta misma norma le otorga.

La ley que establece su organización y funcionamiento mantiene la integración que fija el artículo 136 (7 miembros designados por mayoría absoluta de la Legislatura), con lo cual se avanza en este aspecto reglamentario. Es muy oportuna la salvedad con respecto a los partidos políticos "o alianzas" que efectúa en dos oportunidades la misma norma, atendiendo así a la realidad política del distrito; también la obligatoriedad de respeto a la proporcionalidad en la designación de los miembros restantes del Presidente, cargo que está reservado a la propuesta de la representación de la principal oposición en la Legislatura -en similar sentido que lo establecido por el artículo 85 de la Constitución Nacional-, acentuando así el objetivo de control.

\section{CAPÍTULO QUINTO - DEFENSORÍA DEL PUEBLO}

El artículo 86 de la Constitución Nacional incorporado por la reforma de 1994 elevó con jerarquía constitucional el instituto del Defensor del Pueblo, el cual ya había sido receptado a nivel legislativo por la Ley No 24.284 (modificada parcialmente para adecuar su texto con el mandato constitucional por la Ley No 24.379). Esta figura está instituida allí “en el ámbito del Congreso de la Nación”, con plena autonomía funcional y sin recibir instrucciones de ninguna autoridad por su condición de órgano independiente. Si bien estos rasgos son repetidos por el artículo $137^{\circ}$ de la Constitución de la Ciudad, el constituyente porteño no previó aquí su dependencia de la Legislatura. Pero cabe señalar que tampoco tuvo previsto otorgarle autarquía financiera, ni redactó un párrafo como el que menciona para la Auditoría General ("La ley de presupuesto debe contemplar la asignación de recursos suficientes para el efectivo cumplimiento de sus competencias").

La figura de la Defensoría del Pueblo contenida en este capítulo mejora al instituto federal en ciertos aspectos, a saber: la misión de tutela se amplía de los actos, hechos u omisiones de la administración a los de "prestadores de servicios públicos"; se le otorga iniciativa legislativa; y se incorpora dentro de su ámbito de actuación a las fuerzas que ejerzan funciones de policía de seguridad local, optimizando así su objetivo protectorio. Por otro lado, queda allanado para requerir la información necesaria para el ejercicio de sus funciones sin que las autoridades públicas puedan oponérsele reserva alguna.

Resulta claro, además, que la asistencia de adjuntos "cuyo número, áreas y funciones específicas y forma de designación son establecidas por ley”, en nada alteran el carácter unipersonal del instituto que consagra el primer párrafo de la norma. Pero es confuso, por su parte, la remisión al mismo cuando se señala el procedimiento de designación en el párrafo quinto, no así en su remoción -únicamente por juicio político, en los términos del mecanismo previsto en los artículos $92^{\circ}$ a $94^{\circ}-$. La particularidad de su naturaleza jurídica hace que el Defensor del Pueblo deba reunir las condiciones establecidas para ser legislador, con iguales inmunidades y prerrogativas, a la vez que le alcanzan las inhabilidades e incompatibilidades de los jueces, según lo establece el sexto párrafo del artículo 137º de la Constitución. 


\section{CAPÍTULO SEXTO - ENTE ÚNICO REGULADOR DE LOS SERVICIOS PÚBLICOS}

Una normativa de avanzada dentro del derecho constitucional económico es el cuerpo previsto en los artículos $138^{\circ}$ y $139^{\circ}$ de la Constitución de la Ciudad. La política desregulatoria y de privatizaciones llevada adelante en los años ' 90 a nivel nacional no encontró en los entes reguladores establecidos desde entonces -algunos por acto legislativo, otros por simples decretos del PEN- el imprescindible resguardo de los consumidores y usuarios de los servicios públicos, sin lugar a dudas el eslabón más débil de la cadena de producción económica. El mandato constitucional contenido en el artículo 42 de la Ley Fundamental se vio, así, convertido casi en una simple cáscara de nuez. Por ello, el constituyente local decidió otorgarle jerarquía constitucional al Ente Único Regulador de los Servicios Públicos, con personería jurídica propia, independencia funcional, autarquía y legitimación procesal.

Este Ente está instituido en el ámbito del Poder Ejecutivo, cuyo Jefe de Gobierno propondrá a la Legislatura la designación del Presidente. Esta otorgará su acuerdo junto a los restantes cuatro miembros del Directorio que la misma proponga (cfr.: inciso 24 del artículo 80). Dos características apuntan a profundizar los mecanismos de participación ciudadana: la designación de los integrantes del Ente previa presentación en audiencia pública, y la necesaria representación de un vocal en nombre de las organizaciones de consumidores y usuarios.

\section{CLAÚSULA DEROGATORIA. LA AUTONOMÍA PORTEÑA: UNA ASIGNATURA PEN- DIENTE}

El artículo $140^{\circ}$ es realmente una sorpresa de sabor ambivalente. Si la confrontamos con la cláusula transitoria segunda -que establece que "las disposiciones de la presente Constitución que no puedan entrar en vigor en razón de limitaciones de hecho impuestas por la Ley No 24.588, no tendrán aplicación hasta que una reforma legislativa o los tribunales competentes habiliten su vigencia"-, nos entran dudas con respecto a la verdadera voluntad de la Convención en cuanto a la operatividad del texto constitucional. Por otro lado, esta disposición pareciera entrar en colisión con el carácter fundacional ya comentado que el mismo Preámbulo establece.

Pero si le oponemos a su texto lo previsto en la cláusula transitoria vigesimotercera ("Hasta tanto se constituya la Legislatura continuarán vigentes las instituciones del régimen municipal con sus correspondientes regulaciones, en la medida que no se opongan o no hayan sido expresamente derogadas por esta Constitución"), o a la misma previsión de fe de erratas con la que concluye dicho capítulo transitorio -cláusula vigesimocuarta-, podemos encontrar su razón de ser en este particular y complicado "status jurídico" en que se halla la Ciudad de Buenos Aires hasta alcanzar la autonomía plena que la reforma de 1994 le otorgó en el artículo 129 de la Constitución Nacional, el que ha venido consolidándose con la jurisprudencia reciente de la propia Corte Suprema de Justicia de la Nación. Sólo entonces su "Constitución formal" será, también, la "Constitución material" -en los términos de Ferdinad Lasalle- que los porteńos nos merecemos. Sin mezquindades ni cortapisas: por derecho 
propio. Una autonomía porteña plena que aún hoy- a más de 25 años de la reforma constitucional de 1994- es una asignatura pendiente.

Ciudad Autónoma de Buenos Aires, Enero de 2020.-

RECIBIDO: $30 / 01 / 2020$

APROBADO: $10 / 04 / 2020$ 


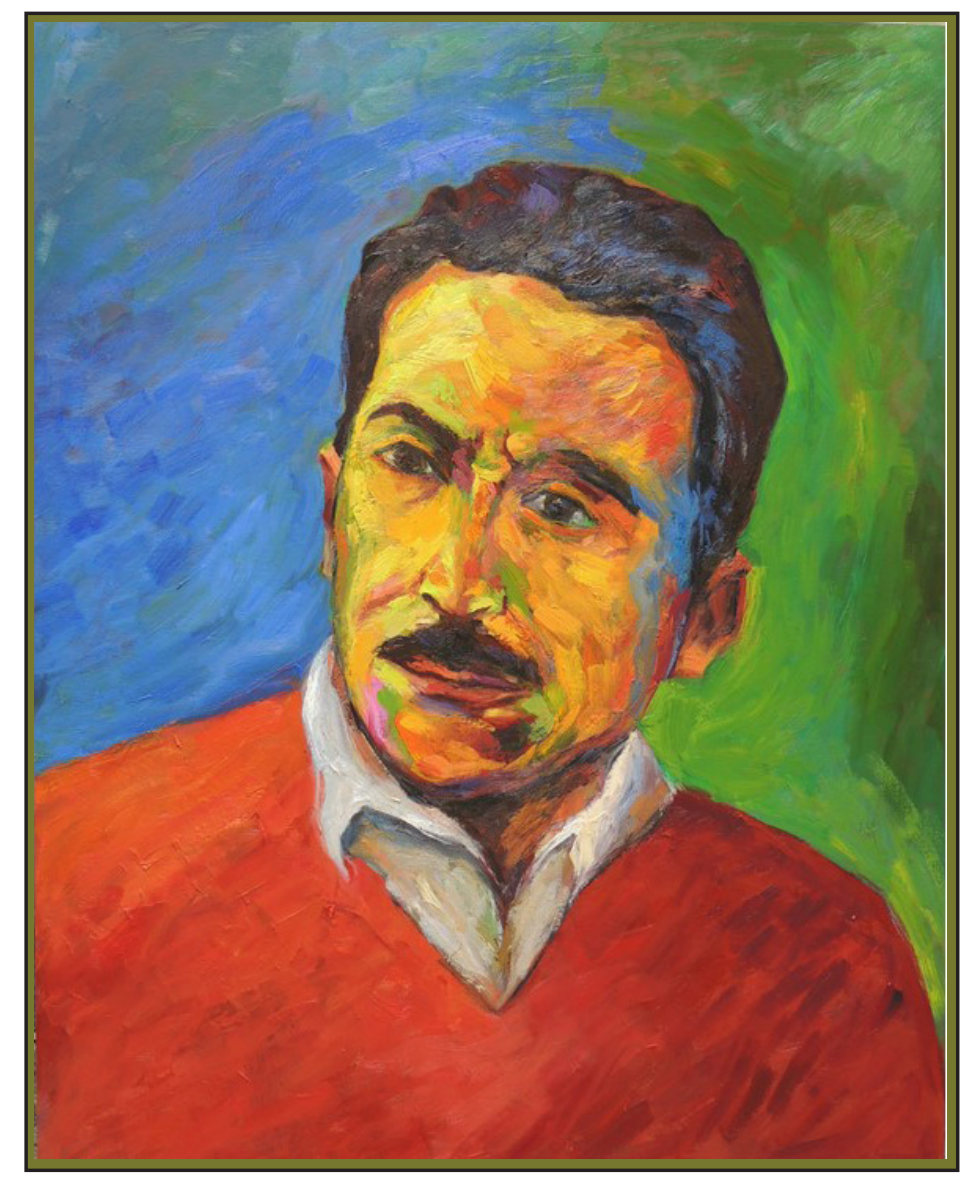

José María Arguedas. Óleo sobre lienzo 81 x $110 \mathrm{~cm}$. Sonia Estrada Melgarejo (pintora peruana, Ancash) 